\title{
INVENTORY CONTROL METHODS IN COMPANIES BY USING INDUSTRY 4.0
}

\section{DOI: 10.17261/Pressacademia.2018.913}

PAP- V.7-2018(66)-p.348-351

\section{Gozde Hilal Zorlu ${ }^{1}$, Melis Gizem Ozturk ${ }^{2}$, Ahmet Murat Koseoglu ${ }^{3}$}

${ }^{1}$ Okan University, Tepeören Mahallesi, Okan Üniversitesi Tuzla Kampüsü, 34959 Tuzla, Istanbul, Turkey. gozdehilalkilic0@gmail.com, ORCID: 0000-0002-2105-3502

${ }^{2}$ Okan University, Tepeören Mahallesi, Okan Üniversitesi Tuzla Kampüsü, 34959 Tuzla, Istanbul, Turkey. melis.ozturk@okan.edu.tr, ORCID: 0000-0001-7927-8467

${ }^{3}$ Okan University, Tepeören Mahallesi, Okan Üniversitesi Tuzla Kampüsü, 34959 Tuzla, Istanbul, Turkey. murat.koseoglu@okan.edu.tr, ORCID: 0000-0002-0656-2798

\section{To cite this document}

Zorlu, G. H., Ozturk, M. G., Koseoglu, A. M. (2018). Inventory control methods in companies by using industry 4.0. PressAcademia Procedia (PAP), V.7, p.348-351.

Permemant link to this document: http://doi.org/10.17261/Pressacademia.2018.913

Copyright: Published by PressAcademia and limited licenced re-use rights only.

\section{ABSTRACT}

Purpose- With the Industry 4.0 manufacturing companies are going through a change and this change also affects inventory control methods due to changed production methods. In this study, effects of new manufacturing ways on stock control methods are examined. Methodology- Literature review made to determine new manufacturing opportunities for the companies and how these new production ways will affect inventory control methods.

Findings- Industry 4.0 created manufacturing options that are not available before therefore inventory control methods are also changing in response to that. Inventory control methods are more focused on Industry 4.0 applications with the current changes in the business environment.

Conclusion- Industry 4.0 as a new concept that is still in development phase are affecting every component of companies not only regarding manufacturing but also concerning inventory control. In the future inventory control methods will go through a change to keep up with Industry 4.0

Keywords: Industry 4.0, logistics, smart factories, stock control methods, supply chain management.

JEL Codes: L9, L90, L99

\section{IŞLETMELERDE ENDÜSTRI 4.0'IN STOK KONTROL YÖNTEMLERINE ETKISi}

\section{ÖZET}

Amaç- Endüstri 4.0 ile birlikte üretici firmalar yeni üretim yöntemleri ile birlikte bir değişim sürecinden geçmektedir. Bu değişim süreci firmaların sadece üretim aşamalarını değil aynı zamanda stok kontrol yöntemlerini de etkilemektedir. Bu çalışmada, yeni üretim yöntemlerinin stok kontrol metodları üzerindeki etkileri incelenmiştir.

Yöntem- Literatür taraması yöntemi ile firmaların kullanabileceği yeni üretim methodları belirlenerek yaşanılan değişimin stok kontrol yöntemleri üzerindeki etkileri incelenmiştir.

Bulgular- Endüstri 4.0 ile ortaya çıkan ve daha önce olmayan üretim yöntemlerinin etkisi ile stok kontrol yöntemleri de değişmekte ve Endüstri 4.0 odaklı hale gelmektedir.

Sonuç- Halen gelişim sürecinde olan Endüstri 4.0 konsepti üretim yapan firmaların sadece üretim açısını değil firmaya bağlı bulunan her alt parçayı etkilemektedir. Bu durum karşııında Endüstri 4.0’a uyum sağlamak için firmaların geçireceği değişim sürecinden stok kontrol yöntemleri de etkilenmektedir.

Anahtar Kelimeler: Akıllı fabrikalar, endüstri 4.0, lojistik, stok kontrol süreçleri, tedarik zinciri yönetimi. JEL Kodları: L9, L90, L99 


\section{GíRiş}

Toplumda yaşanan nüfus artışına bağı olarak teknolojiye duyulan ihtiyaç da artmaktadır. Teknolojinin gelişmesi ile birlikte akıllı cihazlar, akılı ürünler, akıllı binalar, akıllı şehirler, akıllı fabrikalar da hayatımızda yer almaya başlamıştır. Tüm bunlarla birlikte son yıllarda iş dünyasında ve birçok platformda endüstri 4.0 teriminin yer aldığını duymaktayız. Endüstri 4.0, dördüncü sanayi devrimi, dijital devrim gibi farklı isimlerle ifade edilen devrimin özellikle otomasyon sektörünü derinden etkileyeceği anlaşılmaktadır.

Endüstri 4.0 teknolojilerinin üretim sistemleri ile müşteri yönetim sistemleri gibi birçok farklı kaynaktan verileri toplayarak, toplanan verilerin kısa zamanda kapsamlı değerlendirmesi ile operasyonlarda gerçek zamanlı karar vermeyi desteklemek için standart hale gelmesi beklenmektedir. Endüstri 4.0 teknolojilerinin endüstri sektörüne kazandıracakları göz önünde bulundurulduğunda, üretim sistemlerinde kullanılan endüstri 4.0 teknolojilerinin işletmeler için büyük önem arz eden stok kontrol süreçlerinde de etkili şekilde kullanılabileceği öngörülmektedir.

$\mathrm{Bu}$ çalışmanın amacı, endüstri 4.0 teknolojilerinin işletmelerdeki stok kontrol süreçlerinde ne gibi değişiklikler yapabileceğini değerlendirilmektir. Bu kapsamda çalışmada endüstri 4.0’ın stok kontrol süreçlerinde kullanımı değerlendirilmiştir.

\section{LITERATÜR INCELEMESI}

\subsection{Stok Kontrolü}

Literatürde stok tanımına baktığımızda; stoklar üretim süreçlerinde doğrudan veya dolaylı olarak mal ve hizmetlere katılan malzemelerin maliyeti olarak tanımlanmaktadır. (Tekin, 2003) Başka bir tanıma göre ise depoda yer alan her malzeme stok olarak kabul edilir. Stokların parasal tutarı ve miktarı ile stoklar ölçülür. (Kobu, 2014)

Stok kontrolü ile; toplam stok maliyetlerini minimuma indirgeyebilecek bir stok seviyesine ulaşma olanağı elde edilmektedir. Bu sebeple tüm işletmeler kendi mali gücüne, kendi yapısına, ürettiği mal ve hizmetin çeşidine göre bir stok kontrol sistemi belirler ve uygular. (Ayanoğlu, 2005) Stokların kontrolünü sağlamak amacıyla stok miktarını düşük tutmak yerine ihtiyaç halinde kullanılabilecek miktarda ve düşük maliyetle stok bulundurulmalıdır.

İşletmelerin stok yönetiminde yaşadığı problemleri en genel ifade ile açıklayacak olursak; stoklanacak malzemenin sipariş zamanını ve miktarını işletmelerin net olarak belirleyememesinden kaynaklanmaktadır. Fakat stok yönetimi ile ilgili problemler; talepteki belirsizlikler, üretim aşamasındaki çeşitlilikler, tedarik sürecinde yer alan birimler arasındaki sevkiyat sürelerinde yaşanan aksamalar ve değişkenlikler nedeniyle oldukça karmaşık hale gelebilmektedir. Farklı tedarik zinciri yapıları bulunan işletmeler için en optimum stok modellinin sunan matematiksel modeller geliştirilmiş olsa da stok kontrol modellerinin gerçek hayata olan yakınlığı arttıkça matematiksel modellerinde karmaşıklığı artmakta ve çözümlenmesi güç hale gelmektedir. (Sezen, 2004)

Stokların verimli bir şekilde yönetilmesi tüm işletmeler için planlama, satın alma, satış ve maliyetlendirme çalışmalarının başlangıcıdır. İşletmelerde bulunan stokları en genel ifade ile yarı mamul, hammadde, işletme malzemeleri, yardımcı malzeme ve ürün stokları olarak sınıflandırmak mümkündür. (Acar ve Köseoğlu, 2014)_Stok kontrol modellerinin sınıflandırılmasında ise talep değişkeni temel belirleyicidir. Talep türüne göre stok kontrol modelleri olasılıklı modeller ve deterministik modeller olarak ikiye ayrılmaktadır. (Sulak, 2008) işletmeler tarafından talep miktarının net olarak bilindiği durumlarda deterministik modeller, talebin olasılıksız diğer bir deyişle bağımsız olduğu durumlarda, olasılıklı modeller uygulanmaktadır.

İşletmeler mali imkanlarına, işletme yapısına, yönetim politikalarına, büyüklüğüne, üretim türlerine vb. faktörleri göz önünde bulundurarak bir stok kontrol sistemi uygular. Bu sistemlerde uygulanan yöntemler gözle kontrolden, basit sayma ve bilgisayarın desteğinde karmaşık probabilistik modellere kadar değişenlik gösterebilir. İşletmeler uygulayacağı stok kontrol yöntemini seçerken bu faktörlerin yanı sıra bilgi işlem, personele ilişkin olanaklar ve haberleşmeyi de göz önünde bulundurmalıdır. (Kobu, 2014)

\subsection{Endüstri 4.0 Devrimi}

Çok yeni bir kavram olmasına rağmen endüstri 4.0, ilk olarak Almanya Eğitim ve Araştırma Bakanlığı tarafından sürdürülebilir kalkınma stratejisini devam ettirmek ve geliştirmek amacı ile yapılan çalışmalarından biridir. Bakanlık sürdürülebilir kalkınma projesinde değişik alanlar ve temalar belirlemiş ve bunlardan birisine de Almanca'da “Industrie 4.0" olarak adlandırılan “Endüstri 4.0" adı verilmiştir. Bu çalışmaların devamında Endüstri 4.0 strateji belgesi sanayinin en önemli fuarlarından biri olan 2011 Hannover Messe fuarında yayınlanmıştır. (Yönetim Bilişim Sistemleri Dergisi, 2017)

Teknolojinin hızla ilerlemesi ile ürünlerin üretim aşamaları değişmeye başlamıştır. Bu değişime bağlı olarak akıllı ürünlerin müşteri ihtiyaçlarına göre planlanması sağlanmış ve bu durum endüstri alanında rekabetle birlikte ürünlerin yaşam döngülerinin kısa zamanda tamamlanmasını da beraberinde getirmiştir. Bu karmaşık düzen, üretimde yer alan ana unsurlarla internet, mobil cihaz, sensörler ve diğer akılı cihazları birleştirme fikrini ortaya çıkarmıştır. Bu fikir neticesinde endüstri 4.0 kavramı ortaya çıkmıştır. (Bozkurt ve Durdu, 2016)

Ayrıca günümüzde mevcut üretim paradigması sürdürülebilir değildir. Bir taraftan endüstriyel üretim, küresel iklim ısınması ve çevre kirliliği gibi çevresel bozulmaların çoğuna neden olmakta, öte yandan petrol ve kömür gibi yenilenemez kaynaklardan çok fazla tüketilmektedir. Buna ek olarak, nüfusun yaşlanmasından ötürü işgücü arzı azalmaktadır. Bu nedenle, endüstrinin radikal bir değişime ihtiyacı vardır ve bu değişikliği Endüstri 4.0 ele almaktadır. (Wang vd., 2015)

Endüstri 4.0 genel olarak dört yönü kapsamaktadır. 
a. Fabrika: Endüstri 4.0'ın ana yapılarından biri olan fabrika, sadece makineler, sensörler, aktuatörler, konveyörler, robotlar gibi bütün üretim sistemleri ile bağlantılı olan ve otomatik olarak bilgi alışverişi yapan değil, aynı zamanda üretim sürecini kontrol etmek ve fabrika sistemini yönetmek için bilinçli ve akıllı olacaktır.

b. İş: Endüstri 4.0; çeşitli şirketler, fabrikalar, tedarikçi, lojistik, kaynaklar, müşteriler vb. arasında var olacak tam bir iletişim ağı anlamına gelir

c. Ürünler: Akıllı ürünlerin üretiminde; endüstri 4.0 teknolojilerinden yararlanılacak ve sonuçta yeni bir ürün türü oluşturulacaktır. Oluşturulan bu ürünler; bilgi taşıyan işlemci, tanımlanabilir bileşenler ve gömülü detektörler sayesinde üretim süreçlerinde ve üretim sonrası süreçlerde de izlenilebilecektir.

ç. Müşteriler: Müşteriler siparişlerini verdikten sonra üretimin herhangi bir aşamasında, siparişlerini değiştirebilecek veya ürüne ilave özellikler ekleyip, çıkarabilecektir.

Çalışmada nitel araștırma yöntemlerinden literatür incelemesi yöntemi kullanılmış ayrıca ișletmelerin stok kontrol süreçlerindeki problemleri ve endüstri 4.0 teknolojileri incelenmiştir. Çalışma sonuncunda endüstri 4,0'ın stok kontrolüne etkileri değerlendirilmiştir. Ayrıca endüstri 4.0 teknolojileri ve bu teknolojilerin fabrika, iş, ürün ve müşteri alanlarında stok kontrol süreçlerini nasıl etkileyebileceği değerlendirilmektedir.

\section{BULGULAR VE TARTIŞMA}

Yapılan literatür taramasında, endüstri 4.0 ve stok kontrol süreçleri ile ilgili birçok kaynağa rastlanmış ve ilgili bölümlerde genel bir çerçevede açıklamıştır. Genel olarak Endüstri 4.0 teknolojilerinin uygulanacağı alan üretim sistemleri olarak öngörülmektedir. Endüstri 4.0 uygulamaları, üretim süreçlerinin tümünde, kas gücünü ortadan kaldırarak dijital sistemler üzerinden üretim yapmayı amaçlamaktadır.

Üretim yönetimi miktar, kalite, zaman ve maliyet için en uygun değeri bulmaya çalışır. Farklı bir deyiş ile üretim yönetimi mamullerin; miktar, özellik, yer ve zaman açısından değerlendirildiğinde en düşük maliyeti sağlayan çözümü bulmaya ve bu sayede; tüketici isteklerini fiyat, zaman, miktar ve kalite açısından en iyi şekilde karşılamaya, mümkün olduğu kadar stok düzeyini düşük tutmaya veya stok devirlerini arttırmaya, işletmenin kas gücü ve makina kaynaklarından yararlanmasını arttırmaya çalışır. (Kobu, 2014)

Stok kontrol süreçleri ve endüstri 4.0 uygulamaları ortak bir paydada birleştirildiğinde; belki bugün kullandığımız birçok sistem ve iş gücü ortadan kaldırılarak maliyet, zaman ve emek tasarrufu sağlanabilecektir. Söz konusu tasarruflar endüstri 4.0 teknolojileri kullanılarak aşağıdaki şekillerde gerçekleştirilebilir.

a. Siber Fiziksel Sistem Teknolojierinin stok kontrol süreçlerine etkileri değerlendirildiğinde; akıllı ürünlerin sahip olduğu bilgi taşıyan işlemci, tanımlanabilir bileşenler ve gömülü detektör özellikleri sayesinde ürünler gerçek zamanlı olarak izlenebilecek ve ürüne oluşabilecek talep tahminleri yapılabilecektir. Müşterilerin üretim süreçlerine dahil edilmesiyle işletmeler, müşterilerini tanıyacak ve müşteri ihtiyaçlarına göre ürün stoklayacaktır. Siber fiziksel sistemlerin kullanımı ile taleplerde, stok seviyesinde veya hatalarda meydana gelen değişikliklere hızlı bir şekilde tepki verilebilecek ve bu durum genel atık azaltımını sağlayacaktır. (Uglovskaia, 2017)

b. Robotlar Teknolojierinin stok kontrol süreçlerine etkileri değerlendirildiğinde; servis robotları fabrikalar, depolar, hastaneler ve diğer halka açık alanları dolaşarak üretim süreci boyunca parçaları ve malları getirmek, ürünleri taşımak, palet yüklemek gibi işlerinin yanı sıra makinelerin ve stokların durum düzeylerini kontrol etmek amacıyla bağımsız veya insan asistanı olarak çalışabilir. (Fırat, 2017) Birbirleriyle iletişim halinde olan makine ve robotlar büyük üretim serilerinin pratik bir şekilde üretilmesine imkân tanıyacak ve esnek fabrikaların oluşmasını sağlayacaktır. İleri otomasyonda (insansız üretim hatlarında), benzetim ve veri tekniklerinin kullanımıyla üretim hızı artacak, ihtiyaç duyulan stok miktarları azalacak, bu durum da verimliliğin artmasını sağlayacaktır. (Pamuk ve Soysal. 2017)

c. Nesnelerin İnternetinin stok kontrol süreçlerine etkileri değerlendirildiğinde; Aynı anda birden fazla birim tarafından stokların depo içindeki yerleri ve miktarları hakkında bilgi sahibi olunabilir.

ç. Bulut Bilişim Teknolojilerinin stok kontrol süreçlerine etkileri değerlendirildiğinde; işletmeler, fabrikalar, tedarikçi, lojistik, kaynaklar, müşteriler vb. arasında gerçek zamanlı iletişim sağlayarak, işletmeler tarafından oluşacak talepler üzerine üretim yapacak ve bu durum da stok seviyelerinde düşüşe neden olabilecektir.

d. Büyük Veri Analitiğinin stok kontrol süreçlerine etkileri değerlendirildiğinde; gerçek zamanlı verilerin analizi sayesinde stok kontrol süreçlerinde meydana gelen bir sorun önceden tespit edilip giderilebilir. Üretim ve makine çalışma süreleri hakkında bilgi sahibi olmamızı sağlayarak stok kontrol süreçlerinde verimliliği arttırabilir

e. Yatay ve Dikey Entegrasyonunun stok kontrol süreçlerine etkileri değerlendirildiğinde; dikey entegrasyonda siber fiziksel sistemlerin kullanımı ile fabrikaların ve üretim sistemlerinin talep seviyelerine, stok durumlarına, arıza/bakım konularına anlık reaksiyon verebilmeleri söz konusu olacaktır.

f. Katmanlı Üretimin stok kontrol süreçlerine etkileri değerlendirildiğinde; katmanlı üretim ile yüksek performanslı, merkezden bağımsız toplu üretim sistemleri nakliye mesafelerini ve eldeki stokları azaltacaktır. Stok maliyeti minimize edilecek, üretimin ucuzlamasını sağlayacaktır. (Uglovskaia,2017) İşletmelerin özelliklerine göre, bazı işletmeler stok bulundurmayabilir veya gerektiğinde katmanlı üretim teknolojileri ile ihtiyaç halinde üretim yapabilir. Talep üzerine üretim yapmasına izin vereceğini ve bunun da stokta düşüşe neden olacağını beklenmektedir.

g. Artırılmış Gerçekliğin stok kontrol süreçlerine etkileri değerlendirildiğinde; stok kontrol süreçlerinde görevli personel değişen stok çeşitlerine daha kolay adapte olacak ve stokların depoda iken muhafazası ve bakımı konularında bilinçli hale gelecektir. Böylece depoda karşılaşılabilecek olumsuzluklar önceden tahmin edilebilecektir. 
Stok yönetim süreçlerinde toplam maliyeti minimize edecek şekilde doğru zamanda ve doğru miktarda sipariş verilmelidir. Aksi halde işletmeler sipariş vermesi gereken malzemelerin zamanını ve miktarını tam olarak belirleyememesine ilişkin stok problemleri ile karşı karşıya kalabilir. İşletmelerin bu problemlerle karşı karşıya kalmaması için endüstri 4.0 teknolojileri kullanılarak hem ürünler hem depolar akıllı hale getirilmelidir.

\section{SONUÇ}

Özerk robotlar, yapay zekâ ile birlikte nesnelerin interneti, büyük veri ve bulut bilgi işlem gibi birçok teknolojinin kullanılmasıyla Endüstri 4.0 çağının başlaması hayatımızda şüphesiz birçok şeyi değiştirecektir. Bu değişikliklerin üretim sistemlerinde başlayıp daha sonra tedarik zinciri içinde birçok alana yayılması beklenmektedir. Stok kontrol süreçleri de bu alanlardan bir tanesidir.

Endüstri 4.0 teknolojilerinin stok kontrol süreçlerinde kullanılmasıyla gelecekte stok kontrol sistemleri yeni bir boyut kazanacaktır. Stoklanacak malzeme miktarı ve çeșidinin azalması, insan faktörü olmadan kontrollerin yapılması, bazı fabrikaların tamamen stoksuz üretime geçmesi gibi düşünceler bunlardan bazılarıdır. Gelecekte, Endüstri 4.0 ile öngörülen üretim ortamı sağlandığında belki de bugün geliştirmeyi düşündüğümüz birçok stok kontrol yöntemi yerini tamamen siber fiziksel sistemlerle donatılmış depolara bırakacak ve biz ihtiyaç duyduğumuz her bilgiye kısa zamanda ve anlık olarak ulaşabileceğiz. Ek olarak insan faktörüne bağlı olarak oluşan hataların azalması, iş sağlığı ve güvenliği konusundaki gelişmeler, süreçlerin hızlanması, müşteriye anlık bilgi akışı ile müşteri memnuniyetinin artması gibi faktörler de sonuç kısmındaki öngörülere eklenebilir.

\section{KAYNAKLAR}

Acar, A. Z., Köseoğlu, A. M. (2014). Lojistik yaklaşımıyla tedarik zinciri yönetimi.

Ayanoğlu, M. (2005). Üretim yönetimi (Ders Notları). Adapazarı: Sakarya Kitabevi, s.336.

Bozkurt, Ü. İ., Durdu, A. (2016). Akıllı fabrikalarda dağıtıımış kontrol sistemleri uygulaması ve RFID yaklaşımı.

Kobu, B. (2014). Üretim yönetimi. Beta Yayınevi, 17. Baskı İstanbul.

Tekin, M. (2003). Üretim yönetimi. Cilt 2, Günay Ofset, Konya.

Pamuk, N. S., Soysal, M. (2017). Yeni sanayi devrimi endüstri 4.0 üzerine bir inceleme.

Sezen, B. (2004). Tedarik zincirinde stok yönetimi problemleri için elektronik tablolar yardımı ile simülasyon uygulaması. Yönetim ve Ekonomi, Cilt: 11, Sayı:1,

Sulak, H. (2008). Stok kontrolü ve ekonomik sipariş miktarı modellerinde yeni açıımlar: ödemelerde gecikmeye izin verilmesi durumu ve bir model önerisi. Doktora Tezi, Süleyman Demirel Üniversitesi, Sosyal Bilimler Enstitüsü, Isparta.

Uglovskaia, E. (2017). The new industrial era industry 4.0 \& Bobst company case study. 